\title{
Modification of a Design of a Wheel-Tracked Chassis of a Mine Clearing Ma- chine
}

\section{Miroslav Blatnický, Ján Dižo, Jozef Harušinec}

Department of Transport and Handling Machines, Faculty of Mechanical Engineering, University of Žilina. Univerzitná 8215/1， 01026 Žilina. Slovak Republic. E-mail: miroslav.blatnicky@fstroj.uniza.sk, jan.dizo@fstroj.uniza.sk, jozef.harusinec@fstroj.uniza.sk

This article is aimed at design of a support and a tension mechanism to be mounted on a wheel-tracked chassis of a mine clearing machine. The subject machine serves to detect and disposal mines in terrain. The main advantage of this machine is the possibility to use it from the safe distance thanks a remote control. The wheel-tracked chassis mounted on the machine ensures that the machine is able to overcome extreme obstacles of a terrain. The solved design of the wheel-tracked chassis can be modifying to move using just wheels for better driving properties on metalled roads. Current design of the wheeltracked chassis goes out from the older technical solution, which has been designed for a four-wheeled machine. The latest version of the chassis is designed for a six-wheeled machine. Application of an original structure of the chassis meets problems consisted in formation of cracks in tracks structure therefore the current structure of tracks has to be modified in order to meet all requirements in term of strength and long-term operation. At the same time, two design of a tension mechanism are presented. A tension mechanism is additional device, which will be mounted to the chassis and it will ensure the optimal position of tracks in every load case.

Keywords: Mine clearing machine, Wheel-tracked chassis, Strength analysis, Tension mechanism

\section{Introduction}

Many countries in the word are still befallen by war conflicts. Such conflicts have politician or religious character. These severe doings mean that many types of weapons are used. A landmine is one of such wheapons. This treacherous wheapon exposes citizen long time after armed conflicts. Mine clearing machines are intended to detect and deactivate landmines. The mine clearing machine Božena 5 is of such machines (Fig. 1).

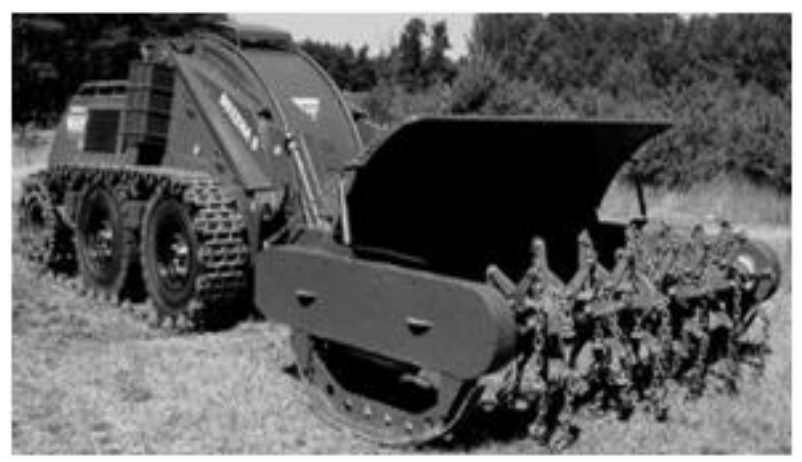

Fig. 1 The mine clearing machine Božena 5

The principle of a work aktivity of the mine clearing machine is, that steel swipl impact on a grand. When a swipl hit the mine, it exploses. Steel swipl rotate by means of a rotating cylinder, to which they are connected by steel chains. The machine is remotely controlled. It is equipped by a turbocharged engine Tatra with the power of $270 \mathrm{~kW}$. It is intended to be used in very difficult and rugged terrain. The front part of the machine is adjusted for various work equipment. The chassis can uses either tracks or wheels.

\section{The wheel-tracked chassis used for the machine}

The wheel-tracked chassis is a chassis, which is assembled from parts of a wheel chassis and tracked chassis or their mutual combination. Such chassis are used for various works in a difficult terrain. The technical solution of these chassis are different, because there are many options, how there is possible to combine these two kind of chassis in order to reach required properties.

A wheel-tracked chassis has to be able to withstand loads, which are generated by a dead machine weight, by its activities, by its moving in a rugged terrain in various climate conditions. The chassis has to ensure controllability and handling. In the case of driving of a machine on longer distance a wheel chassis is preferred.

\subsection{Structure of a tracked chassis}

In case of tracked chassis total mass is distributed on relatively large surface. It allows transmitting great 
driving and braking forces. The large contact patch ensures low specific pressure on ground dispate of quite big total mass of a machine, further good stability, sufficient terrain throughput, possibility to move on an unpaved road and overcome great climbs. Thanks these features tracked machnies can operate in a soft, rugged and sloping terrain. Basic parts of a tracked chassis are shown in Fig. 2, where following parts are marked: 1 - a drive gear wheel, 2 - a guiding wheel, 3 - a lamination, 4 - a chain link, 5 - an end link, 6 - a carrying plate, 7 - a supporting plate, 8 - a carrier pulley.

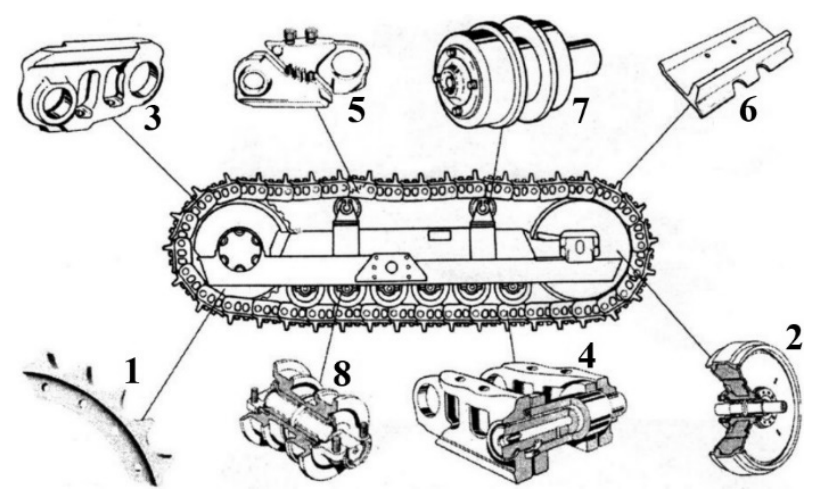

Fig. 2 Basic parts of a tracked chassis

The track is another important part of a tracked chassis. Is circulates around a guiding wheel and a drive wheel. Carrier and supporting rollers ensure righ position of a track and proper loading along its length. The whole track is composed of individual elements connected by pivots.

Tension of a track is important and it is performed either mechanically or hydro-pneumatically. Tension is necessary, because it ensures a proper meshing of a drice gear wheel and a track, its proper position and it avoids excessive tension of a track. A tension mechanism serves as prevention of track rapture in case of any obstacle between a track and a drive wheel as well. It allows pressing of a track and therefore reducing of the stress in the track. The tension mechanism is submitted to the greatest pressure during reverse motion, when the vertical component of the gravitational force and the driving force act on the tension mechanism [1, $10,11,19]$.

\section{Recent design of the chassis construction of a mine clearing machine}

The drive-train of the solved mine clearing machine is created by foru hydro-motors, which drive a drive gear wheel (2) and front gear wheels (1) (Fig. 2). A steering mechanism works based on the principle of the change of circumferential velocity of tracks. One track (4) is braked and other one, which rotates at higher velocity, allows turring of the wheel-tracked machine. This steering system is able even to turn the machine about the vertical axis on the same place. If the machine uses for driving just tracks, there is sufficient to drive only drive gear wheel. But, in case of our solved machine, which has to be able to drive on wheel, there is necessary to drive by the drive-train mechanism also front wheels. The change of a track chassis to a wheel chassis there is necessary to change an intermediate wheel (3). Additional tesnsion of a track is ensured by tension pulleys (5).

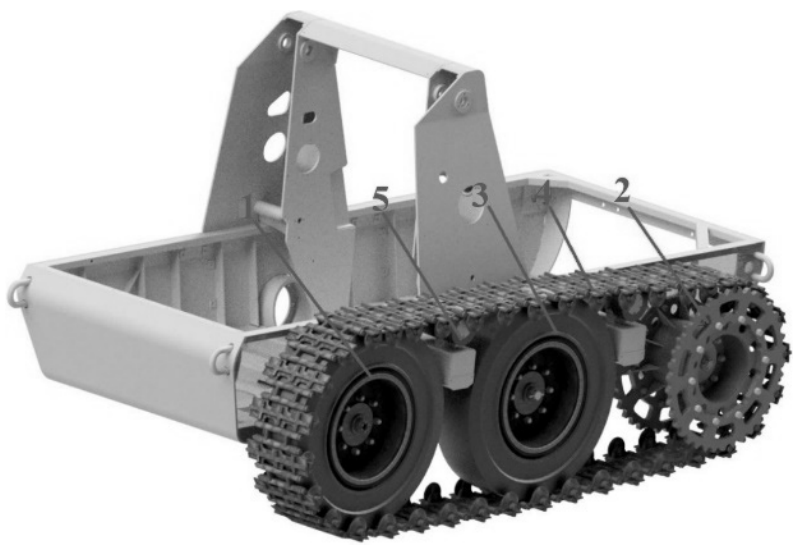

Fig. 3 Amodel of the wheel-tracked chassis of a mine clearing machine

\subsection{Deficiencies of a recent structure of a track chassis}

The recent structure of a wheel-tracked chassis meets the main deficiency, namely, many times the rapture and cracks of tracks ocurr. It is bcause of the fact, that the recent tension mechanism contains two tension pulleys, which position is adjusted by a screw mechanism. It does not include any flexible element. When a machine was operated in rugged terrain and a bigger stone was get in the space between a track and a drive wheel, the track was submitted too great stress, which was resulted to a crack of the track even to the rapture. The similar situation was happened in case of reverse motion in sand, because large amount of sand was stuck between the track and the drive wheel. The track cracked by the described damage is shown in Fig. 4.

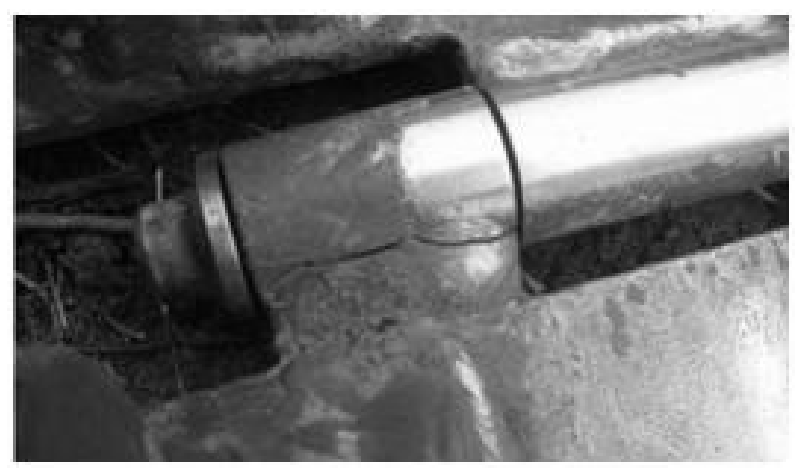

Fig. 4 Location of a crack

The chasis is made of several materials, which differ to each other by chemical composition and thus by 
mechanical properties as well. A shaft of the wheel is made of 34CrNoMo6 steel. This steel is alloyed with chrome, nickel and other alloying elements. I tis characterized by high values of the endurace strength under cyclic and combined load.

For manufacturing of the wheel disc, the S355J2 steel has been used. I tis structural wheel with good weldability and with the yield of strenght of $320-360 \mathrm{MPa}$.

The track of the chassis is made of S500MC steel. It has characterized by the high strenght under hot forming. The yield of strenght of this materiál is of $500 \mathrm{MPa}$. Material properties are effected by technological procesing, methods of manufacturing, chemici composition as well as additional effects, which used components are submitted, e. g. welding, surface treatment, finishing etc. $[9,17,18,25]$.

\section{Design of the front drive wheel support}

The front drive wheel has to be supported adjustable, because the track will be tensioned as well as because of the prevention against rapture of the track.

The drive force is generated by a combustion engine with the power of $P_{e}=270 \mathrm{~kW}$ at 1,800 rpm. The effective power on the drive wheel of $P_{w}=254 \mathrm{~kW}$. The rest of the engine power 270 is used for driving of additional mechanisms. As mentioned above, the drive-train of the machine uses four hydromotors. The power of the one hydromotor is calculated as following:

$$
P_{w 1}=\frac{P_{w}}{4} \cdot \eta_{T}=\frac{254}{4} \cdot 0.86=54.61[\mathrm{~kW}],
$$

where $\eta_{T}$ is the total efficiency of the drive-train mechanism and its values equals 0.86 .

The maximal torque of the one hydromotor $M_{k 1}$ is given by the formulation:

$$
M_{k 1}=\frac{P_{w 1}}{2 \cdot \pi \cdot \frac{n_{o}}{60}}=\frac{54,610}{2 \cdot \pi \cdot \frac{1,536.16}{60}}=339.5[\mathrm{~N} \cdot \mathrm{m}],
$$

where $n_{0}$ are output rotates of the hydromotor and the value of $1,536.16\left[\mathrm{~min}^{-1}\right]$ is calculated for our considered operation conditions.

The hydromotor will be combined with a gerabox, which efficiency is $\eta_{p}=0.8$ and the gear ratio is $i_{p}=38.6$. The torque $M_{k o}$, which will be on the output shaft, is calculated as following:

$$
M_{k o}=M_{k 1} \cdot i_{p} \cdot \eta_{p}=339.5 \cdot 38.6 \cdot 0.8=10,483.76[N \cdot m],
$$

The result force $F_{r}$, which acts on the track, is found out based on dimension of the drive gear wheel. The radius of the pitch circle is $r=0.465[\mathrm{~m}]$. Thus, the mutual relation of the torque $M_{k 1}$, radius $r$ and the result force is:

$$
F_{r}=\frac{M_{k o}}{r}=\frac{10,483.76}{0.465}=22,545.72[N \cdot m],
$$

\subsection{The maximal force in the track}

The track is most loaded in the location of the drive wheel contact. In this location the greatest values of stresses are generated, as we can see in Fig. 5. In other location of the track, values of the stress are lower. The result stress, which has been observed by means of the finite element method, reached values about $200[\mathrm{MPa}]$. This values are not critical, because

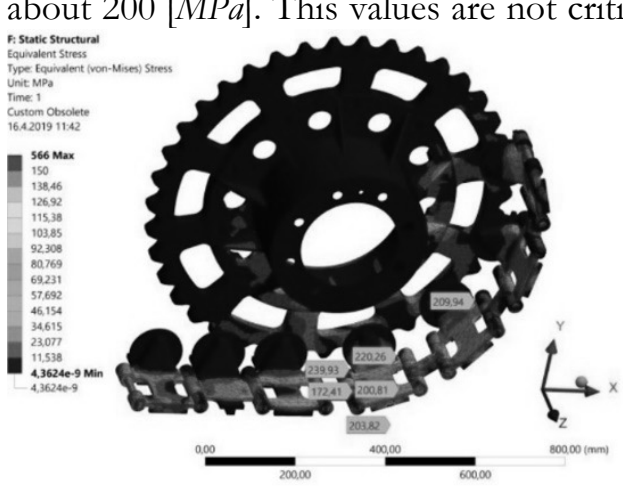

(a)

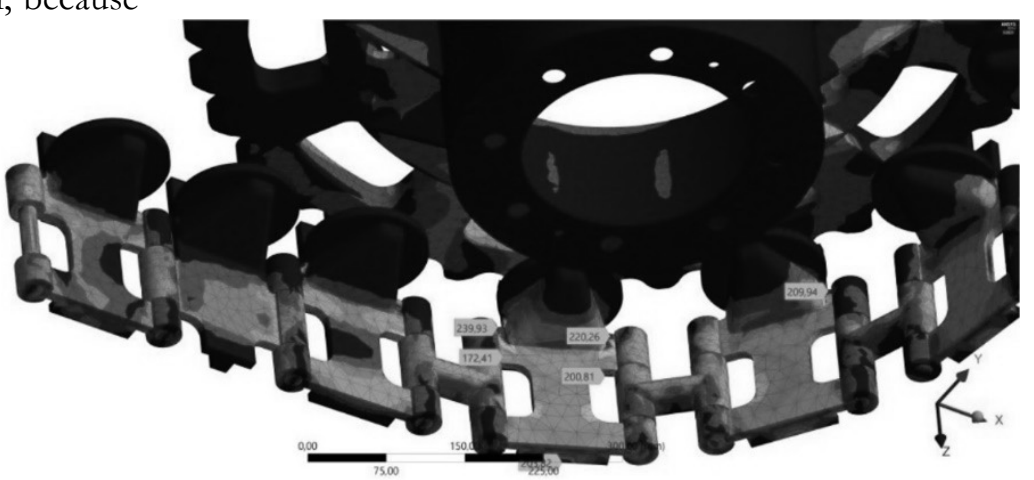

(b)

Fig. $5 \mathrm{FE}$ analysis of the track (a), the detail of the critical location (b) 
One of the possible solutions would be modification of the track geometry in such a manner, that the contact of the drive wheel will be the track axis. Such an approach minimalizes the formation of the adverse bending moment.

\section{Design and analyses of tension mecha- nisms}

In order to avoid such an adverse effect generated in the track, there are designed two variants of a tension mechanism. One technical solution is based on the existence of two guiding rods and other solution contains a linear guidance. These designed technical solutions are shown in Fig. 6.

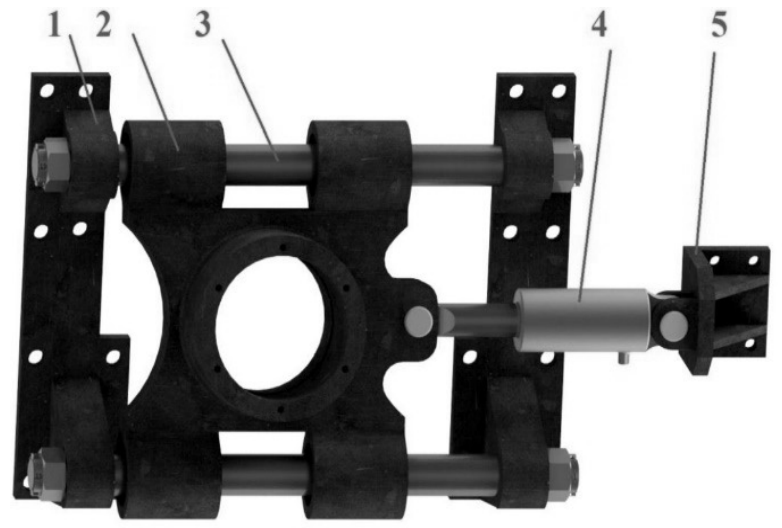

(a)
The first tension mechanism including the guiding rods (Fig. 6a) contains two guidance rods (3), a wheel hub (2), two holders (1). The hub moves in the longitudinal direction. A hydraulic cylinder ensures this movement. The cylinder is mounted on a holder (5).

The other tension mechanism (Fig. 6b) contains a linear guidance. It is composed of the guidance (1), which is mounted on the wheel hub (2) in the shape of a V letter with an angle $90^{\circ}$. The longitudinal movement is ensured by means of this mounting and the track is tense by the hydraulic cylinder (3) as in the first variant. The mounting of the hydraulic cylinder is by the holder (4).

Placing of designed tension mechanisms on the mine clearing machine are shown in Fig. 7.

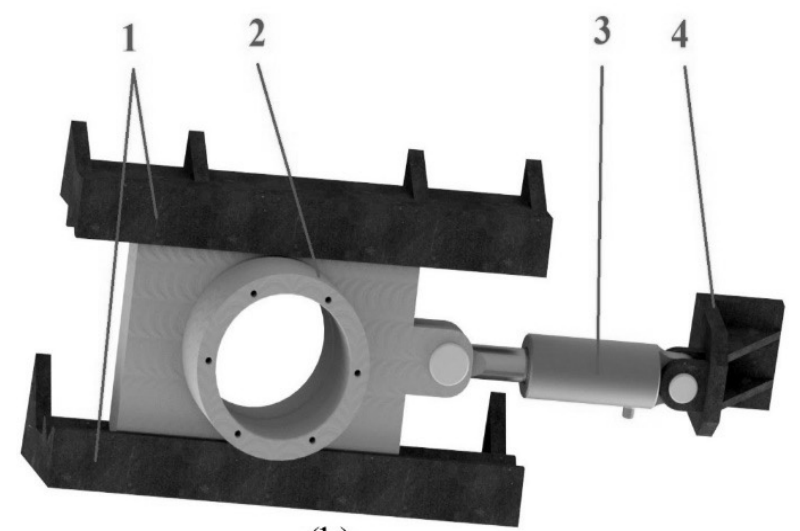

(b)

Fig. 6 A tension mechanism including guiding rods (a) and a tension mechanism including the linear guidance (b)

The total weight of the machine is of $13,090[\mathrm{~kg}]$. The curb weight of the machine is of $10,240[\mathrm{~kg}]$ and the weight of special accessories is of $2,850[\mathrm{~kg}]$. In the design there was considered, that the total weight acts only on the front axle. It means, that this axle is loaded by the load of 128,412.9 [N] and one wheel by the load of $64,206.45[N]$. Based on calculated loads there were performed strength analyses of both variants of tension mechanism. Strength analyses were carried out in

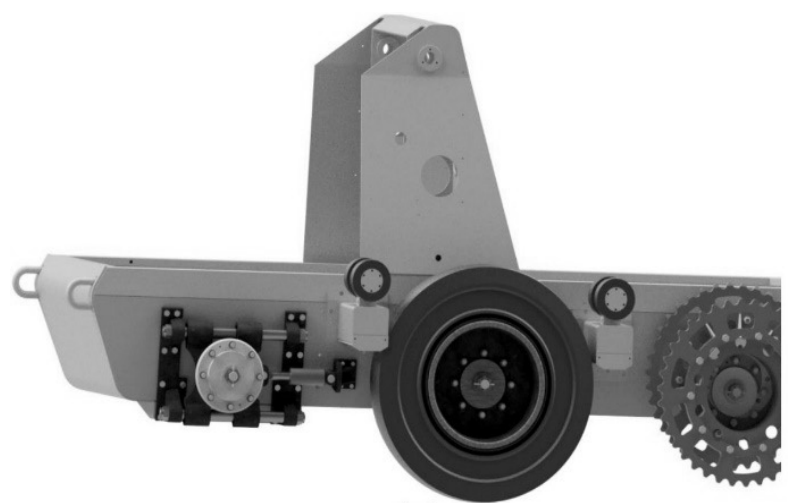

(a) the Ansys finite element software [16]. In this software, there is possible to perform various calculations of mechanical systems [7, 8, 22, 24].

The structure was loaded by the load introduced in the previous section, i. e. 64,206.45 [N]. The structure was loaded in the longitudinal direction by the tension force as well. The tension force has value of $60,000[N]$. There was chosen the standard structural steel with the yield of strength of $250[\mathrm{MPa}]$. Results of strength analyses are shown in Fig. 8.

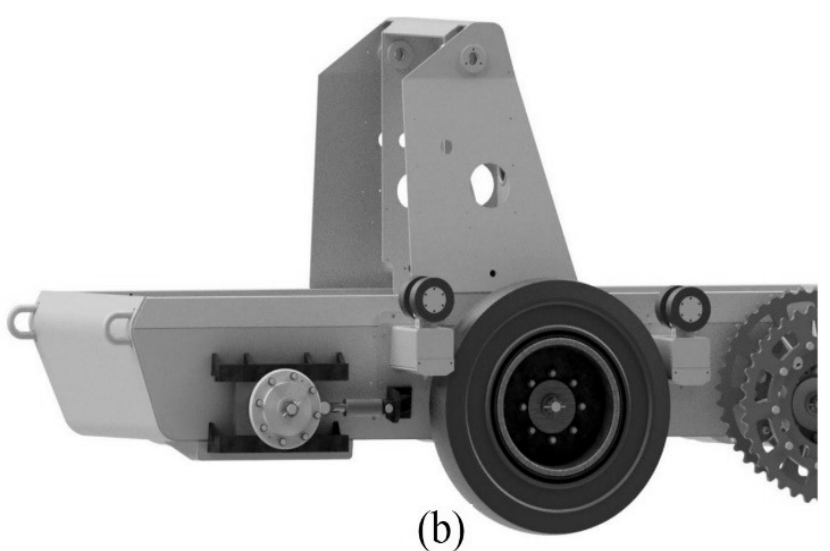

Fig. 7 Positioning of the tension mechanism including guiding rods (a) and placing of the tension mechanism including the linear guidance (b) on the mine clearing machine 


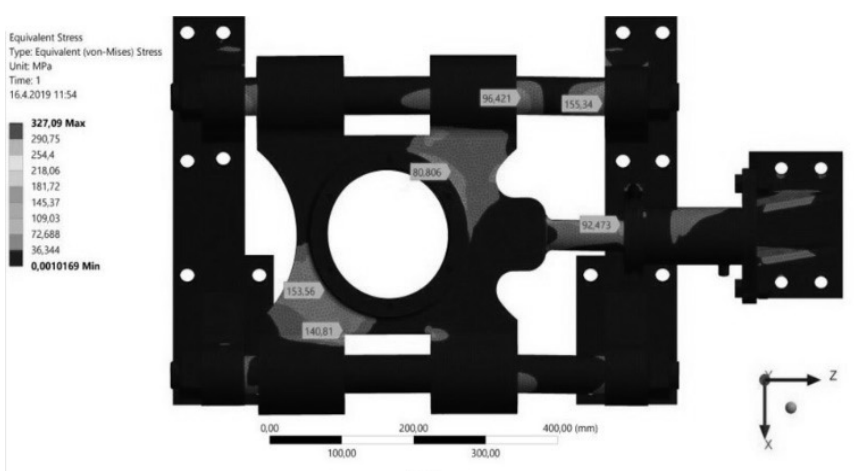

(a)

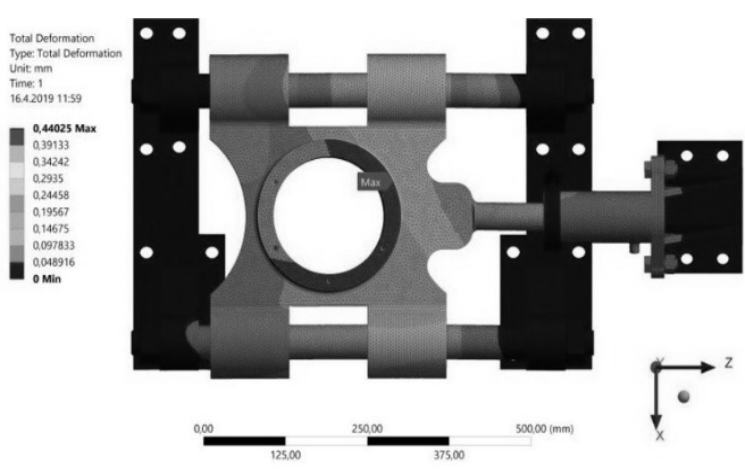

(b)

Fig. 8 The equivalent stress (a) and the total deformation (b) in the tension mechanism including guiding rods

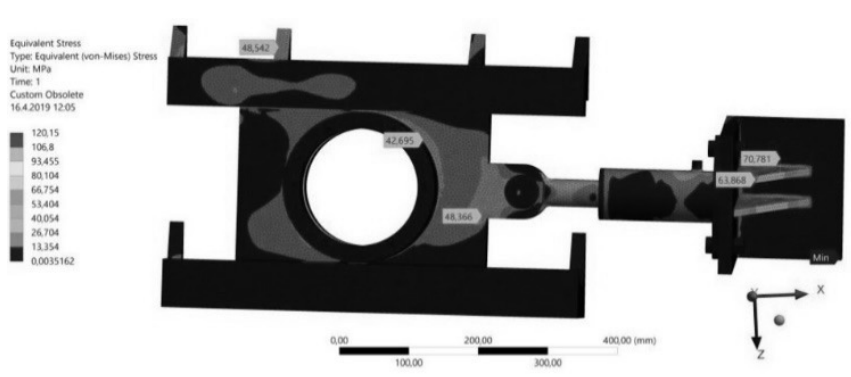

(a)

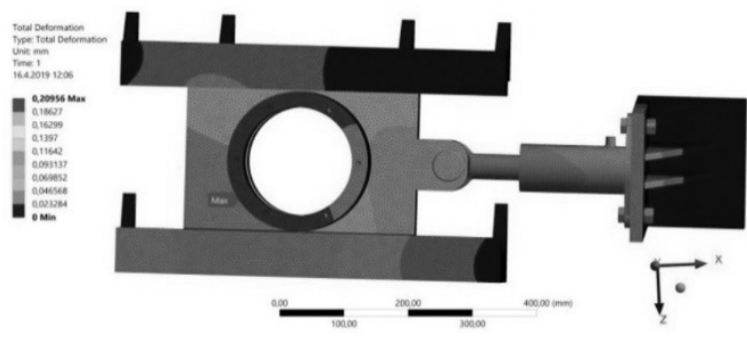

(b)

Fig. 9 The equivalent stress (a) and the total deformation (b) in the tension mechanism including the linear guidance

From results of strength analyses we can see (Fig. 8a) that the maximal stress is reached in the location of a hole and the value is up to $155[\mathrm{MPa}]$. It means, the structure meets the safety requirements, whereas there is under the yield of strength of the used material. Figure $7 \mathrm{~b}$ shows the total deformation of the structure. The maximal displacement of the structure is of $0.44[\mathrm{~mm}]$. The structure is flexible enough. The main advantage if this structure is lower friction, but it is more complicated for production. The attachment of the hydraulic cylinder by means of fix holder is not suitable, because partial deformation and displacement of the hub the total stress in the structure could increase the loading of the cylinder and subsequently it can be damaged. Therefore, the hydraulic cylinder has to be attached on the structure by means of a pin on both sides. This approach ensures partial deflexion and prevents the deformation of the cylinder piston.

The tension mechanism including the linear guidance (Fig. 6b) was loaded by the same loads as the previous analysed structure including guiding rods. The material properties are the same as well. Results of strength analyses are shown in Fig. 9.

By means of this analysis we have found out, that the structure is able to transmit the given load. The resultant maximal stress in the structure does not exceed the value of $100[\mathrm{MP} a$. It follows, that the safety coefficient is high sufficiently, which has the positive effect on fatigue life of this structural unit. The maximal displacement is of $0.21[\mathrm{~mm}]$, which is a half of the value in case of the tension mechanism including guiding rods. Also for this system, there is better to choose the attachment by means of pins on both sides.

The future research in this field will be focused on application of the greated model of the tension mechanism to the entire model of the mine clearing machine to perform dynamic analysis of the mechanism and to observe, how dynamic forces affect individual parts of the mechanism [2, 5, 6, 13]. As the designed tension mechanism will be submitted to the load of uncertain character, i. e. stochastic character mainly considering various speed and irregularities of a surface, it can cause significant undesirable response of the entire mechanical system of the machine [3, 4]. These vibrations can have quite adverse effects in terms of driving properties as well as lifetime of individual elements $[13,21]$.

\section{Conclusion}

The article presents design of technical solutions and strength analyses of the wheel-tracked chassis of the mine clearing machine. The main deficiency of the current state is the fact, that the track of the chassis is damaged. It can mainly happen, when the machine moves back in a slope in sand or when bigger element is between drive wheel and the track. In order to avoid such an unwanted situation, two technical solution of a tension mechanism were designed. One mechanism contains two guiding rods and the other one contains a linear guidance. Both variants meet given safety criteria. The final choice of the tension mechanism depends on economical and production evaluation. 


\section{Acknowledgement}

This work was supported by the Cultural and Educational Grant Agency of the Ministry of Education of the Slo-vak Republic in project No. KEGA 077ŽU-4/2017: Modernization of the Vehicles and engines study program.

\section{References}

[1] DROPPA, P., RIEČIČIAR, M. (2018). Simulation methods used for planetary gearbox analysis. In: Proceedings of $22^{\text {nd }}$ International Scientific Conference Transport Means 2018, pp. 597600. Trakai, Lithuania.

[2] FABIAN, P., GERLICI, J., MASEK, J., MARTON, P. (2013). Versatile, efficient and long wagon for intermodal transport in Europe. In: Komunikacie, Vol. 15, No. 2, pp. 118-123.

[3] FOMIN, O., GERLICI, J., LOVSKA, A., GORBUNOV, M., KRAVCHENKO, K., PROKOPENKO, P., HAUSER, V. (2019). The improved hatch cover construction for universal open box-type wagon from the strenght and durability point of view. In: Manufacturing Technology, Vol. 19, No. 2, pp. 216-221.

[4] GERLICI, J., GORBUNOV, M., KRAVCHENKO, K., KOSTYUKEVICH, A., NOZHENKO, O., LACK, T. (2016). Experimental rigs for wheel/rail contact research. In: Manufacturing Technology, Vol. 16, No. 5, pp. 909916.

[5] GORBUNOV, M., GERLICI, J., KARA, S., NOZHENKO, O., CHERNYAK, G., KRAVCHENKO, K., LACK, T. (2018). New principle schemes of freight cars bogies. In: $\mathrm{Ma}$ nufacturing Technology, Vol. 18, No. 2, pp. 233238.

[6] HAUSER, V., NOZHENKO, O., KRAVCHENKO, K., LOULOVÁ, M., GERLICI, J., LACK, T. (2017). Proposal of a steering mechanism for tram bogie with three axle boxes. In: Procedia Engineering, Vol. 192, pp. $289-294$.

[7] HRABOVSKÝ, P., KOLKOVÁ, Z. (2017). Optimization of CFD model for gravity heat pipes. In: Proceedings of $17^{\text {th }}$ International Multidisciplinary Scientific GeoConference Surveying Geology and Mining Management, SGEM 2017, pp. 451 - 458. Albena, Bulgaria.

[8] HRABOVSKÝ, P., KOLKOVÁ, Z., MOKRÝ, M., NEMEC, P. (2018). Basic CFD model of heat pipe. In: MATEC Web of Conferences, Vol. 168.
[9] JAKUBOVIČOVÁ, L., SAPIETOVÁ, A., MORAVEC, J. (2018). Static analysis of transmission tower beam structure. In: MATEC Web of Conferences, Vol. 244.

[10] KAŠPÁREK, J., JONÁK, M., ŠKOPÁN, M. (2017). Design of the tracked chassis module. In: Proceedings of $21^{\text {st }}$ International Scientific Conference Transport Means 2017, pp. 666670. Juodkrante, Lithuania.

[11] KAŠPÁREK, J., POKORNÝ, P. (2014). Analysis of the dynamics of a virtual prototype wheeled transport machine. In: Proceedings of $18^{\text {th }}$ International Conference Transport Means 2014, pp. 99-102. Kaunas, Lithuania.

[12] KLIMENDA, F., SOUKUP, J., SKOCILASOVA, B. (2018). Propagation of stress waves in thin ortotropic plates. In: Proceedings of $17^{\text {th }}$ International Scientific Conference Engineering for Rural Development, ERD 2018, pp. 1476-1481. Jelgava, Latvia.

[13] LACK, T., GERLICI, J. (2016). Tangential stresses for non-elliptical contact patches computed by means of a modified FASTSIM method. In: Civil-Comp Proceedings, Vol. 110.

[14] LACK, T., GERLICI, J., MANUROVA, M. (2016). Freight car bogie properties analysis by means of simulation computations. In: Manufacturing Technology, Vol. 16, No. 4, pp. 733-739.

[15] MAŇUROVÁ, M., SUCHÁNEK, A. (2016). Determination of stiffness of triple spring built in a bogie of a rail vehicle. In: Manufacturing Technology, Vol. 16, No. 2, pp. 390-396.

[16] MAŇUROVÁ, M., SUCHÁNEK, A. (2016). The analysis of a rail vehicle with a tilting bogie. In: Manufacturing Technology, Vol. 16, No. 5, pp. 1020-1027.

[17] MORAVEC, J. (2017). Electromagnetic forming of thin-walled tubes introduction. In: Proceedings of $26^{\text {th }}$ International Conference on Metallurgy and Materials, METAL 2017, pp. 326331. Brno, Czech Republic.

[18] RUDAWSKA, A., WAHAB, M. A., BARTA, D., PUKALSKAS, S. (2019). The effect of technological and structural factors on the strength of polyethylene andhesive joints. In: Lecture Notes in Mechanical Engineering, pp. 241257.

[19] SOJKA, M., ČORNÁK, Š., DROPPA, P. (2017). Selected problems of tracked vehicle movment modelling. In: Proceedings of $21^{\text {st }}$ International Scientific Conference Transport Means 2017, pp. 493-498. Juodkrante, Lithuania. 
[20] SOUKUP. J., ŽMINDÁK, M., SKOČILAS, J., RYCHLÍKOVÁ, L. (2014). Application of mesh-free methods in transient dynamic analysis of orthotropic plates. In: Manufacturing Technology, Vol. 14, No. 3, pp. 441-447.

[21] ŠŤASTNIAK, P. (2015). Wagon chassis frame design with adaptable loading platform. In: $M a-$ nufacturing Technology, Vol. 15, No. 5, pp. 935940.

[22] ŠŤASTNIAK, P., MORAVČÍK, M., BARAN, P., SMETANKA, L. (2018). Computer aided structural analysis of newly developed railway bogie frame. In: MATEC Web of Conferences, Vol. 157.

[23] SVOBODA, M., SOUKUP, J., PETRENKO, A. (2014). Use of FEM programs in solving ge- neral unbalance simple mechanical system of rigid, flexible stored bodies. In: Proceedings of $52^{\text {nd }}$ International Conference on Experimental Stress Analysis, EAN 2014. Marianske Lazne, Czech Republic.

[24] TARTAKOVSKY, E., FALENDYSH, A., ZINKIVSKYI, A., MIKHEEV, S. (2015). Refining the models of performing service tests of upgraded locomotives. In: Eastern-European Journal of Enterprise Technologies, Vol. 2, No. 3, pp. 26-31.

[25] VATULIA, G., FALENDYSH, A., OREL, Y., PAVLIUCHENKOV, M. (2017). Structural improvements in a tank wagon with modern software packages. In: Procedia Engineering, Vol. 187, pp. 301-307. 